\title{
Graphene Nanoplatelets in Epoxy System: Dispersion, Reaggregation, and Mechanical Properties of Nanocomposites
}

\author{
Jiacheng Wei, Rasheed Atif, Thuc Vo, and Fawad Inam \\ Department of Mechanical and Construction Engineering, Faculty of Engineering and Environment, Northumbria University, \\ Newcastle upon Tyne NE1 8ST, UK
}

Correspondence should be addressed to Fawad Inam; fawad.inam@northumbria.ac.uk

Received 31 August 2015; Revised 9 October 2015; Accepted 20 October 2015

Academic Editor: Bhanu P. S. Chauhan

Copyright (C) 2015 Jiacheng Wei et al. This is an open access article distributed under the Creative Commons Attribution License, which permits unrestricted use, distribution, and reproduction in any medium, provided the original work is properly cited.

The use of graphene nanocomposites in advanced applications has attracted much attention in recent years. However, in order to substitute traditional epoxy reinforcements with graphene, there are still some issues like dispersion, homogenization, and reaggregation. In this paper, graphene bundles dispersed in two-component epoxy system by bath sonication, dispersion state, and reaggregation behavior of graphene in this system have been studied. Light transmittance in ultraviolet-visible spectroscopy has been used to quantify the reaggregation by a series of controlled experiments. After 18 mins sonication of 0.005 wt $\%$ graphene dispersion at $20^{\circ} \mathrm{C}$, the light transmittance decreased from $68.92 \%$ to $54.88 \%$ in liquid epoxy and decreased from $72.80 \%$ to $46.42 \%$ in hardener; while increasing the temperature from $20^{\circ} \mathrm{C}$ to $60^{\circ} \mathrm{C}$, the light transmittance in liquid epoxy decreased from $65.96 \%$ to $53.21 \%$ after 6 mins sonication. With the incorporation of $0.3 \mathrm{wt} \%$ graphene, the tensile strength of nanocomposites increased from 57.2 $\mathrm{MPa}$ to $64.4 \mathrm{MPa}$ and the storage modulus increased from 1.66 GPa to $2.16 \mathrm{GPa}$. The results showed that the dispersion state depends on the function of sonication time and temperature, and graphene has a significant reinforcement effect on epoxy.

\section{Introduction}

Since its discovery in 2004 [1], graphene has rapidly attracted both academic interest and industrial interest because of its outstanding properties such as high surface to volume ratio, high aspect ratio, low electrical resistivity, high thermal conductivity, high strength, and modulus. Figure 1 [2] shows graphene as the building block of all graphitic carbon allotropes with different dimensionalities. For composites, graphene can significantly improve the physical and chemical properties of matrix at extremely small loadings when incorporated appropriately [3-5].

Epoxy is one of the most adaptable and universal high performance thermosets available and has been widely used in aerospace, automotive, marine, construction, electrical, and electronic systems, biomedical devices, adhesives, paints and coatings, and other general consumer products $[6,7]$. The combination of graphene and epoxy has led to a new class of nanocomposites for advanced engineering applications. This has now become an avid area of scientific research as evident in Figure 2. Figure 2 shows the dramatic increase in epoxy/graphene nanocomposites research during the last decade.

However, in practical terms, graphene is not suitable to disperse in epoxy just by simple mixing. This is due to graphene's pronounced tendency to reaggregate in the matrix due to the strong van der Waals force and pi-stacking between separately dispersed graphene sheets $[8,9]$. The maximum improvements in final properties could only be achieved when graphene is homogeneously dispersed in the matrix and external stresses are efficiently transferred through strong graphene-epoxy interface $[10,11]$. This can also be seen for other polymer nanocomposites where it is critical to achieve homogenization and thorough dispersion. Therefore, the dispersion state of graphene in the matrix plays a crucial role for achieving superior properties in epoxy/graphene nanocomposites $[12,13]$.

According to the published research, processing methods significantly affect dispersion of graphene, and it is generally agreed that mechanical stirring is one of the suitable techniques to disperse graphene. However, Yang et al. [14] reported that mechanical stirring of suspended graphene 


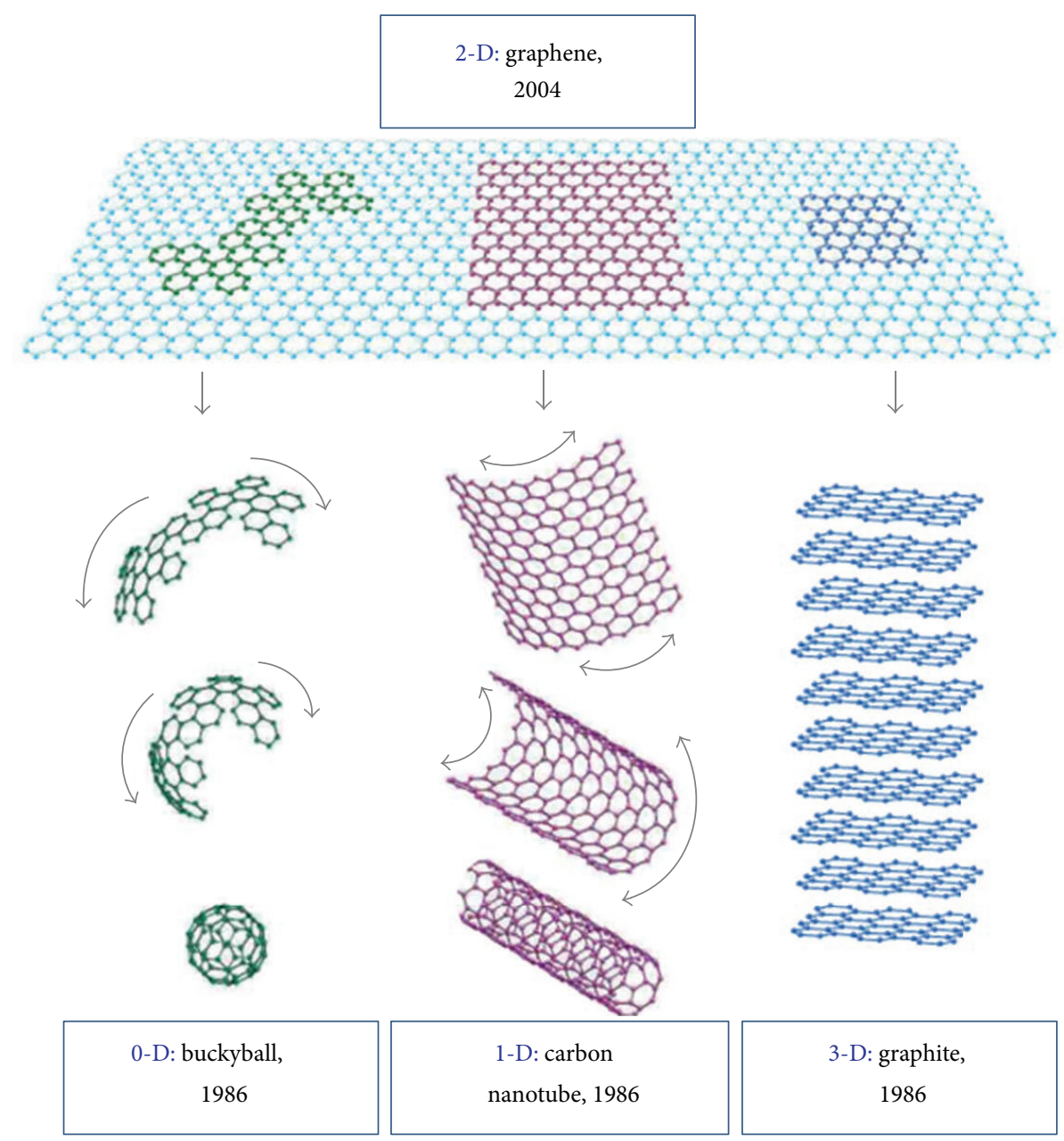

FIGURE 1: Graphene, the building block of all graphitic forms [2].

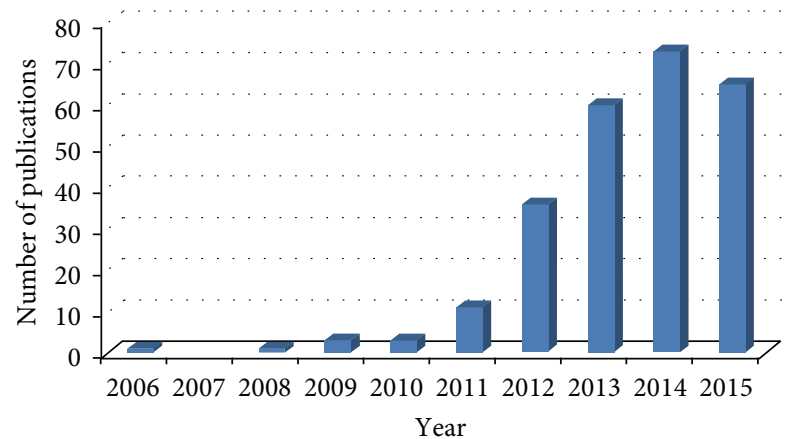

Figure 2: Numbers of publications returned using "graphene epoxy" as keywords searched "in title" in Web of Science (By $30 / 09 / 2015)$

could result in reaggregation between flakes, especially for toluene or benzene suspensions. As a widely adopted technique, sonication proved to be effective to disperse graphene. Several researchers [15-18] reported sonication to be an effective way to suppress the reaggregation of graphene.
Appropriate covalent functionalization of graphene with chemicals retards reaggregation [19]. Appropriately surface modified graphene shows rich solution chemistry, with properties such as dispersibility in solvents and polymers [20]. However, the main drawback of covalent functionalization is the functional groups on the graphene surface which disrupt the band structure and degrade the electronic properties of graphene. Wajid et al. [21] even reported that some surface functionalized graphene acts as insulator due to stronger contribution of the attached chemical groups.

Stable dispersion can also be achieved by wrapping graphene surface by stabilizers such as polymers or surfactants $[22,23]$. As compared to the covalent functionalization of graphene sheets, this kind of noncovalent surface modification can disperse graphene without oxidation or defect formation, thus preserving the integrity of the structure and electronic properties [24]. However, it is generally recognized that the presence of foreign stabilizers is undesirable for most applications because they could decrease the purity of graphene, subsequently deteriorating the unique and exceptional properties of graphene $[25,26]$. 
Using solvents has been widely accepted and regarded as the simplest method to disperse graphene. Choi et al. [27] dispersed graphene in 1-propanol and showed long-term stability of the solution. Other groups dispersed graphene in acetone [28-30], THF [31-33], and DMF [34-36]. However, it should be noted that such dispersions require another step to remove the solvents prior to curing. This can lead to operational complexities and lengthy processing durations which are not desirable. The residual solvent also has detrimental effect on the final properties of the composite material [37, 38]. Beside that, some solvents are expensive and toxic, which may lead to environmental and health and safety implications [39-41].

In this paper, pristine graphene was dispersed in twocomponent epoxy system without using any solvent. The effect of sonication time, storage time, graphene concentration, and sonication temperature on the dispersion and reaggregation of graphene in epoxy, hardener, and their mixtures have been extensively analyzed here.

\section{Experimental Details}

\subsection{Materials}

2.1.1. Epoxy Matrix System. The epoxy matrix used in this study consists of EPOPHEN EL5 bisphenol A based liquid epoxy (EP) and EPOPHENEHA 57 diamine hardener (HD), purchased from Polyfibre UK Ltd. This epoxy system is a multipurpose resin offering good all-round properties with the epoxy group content of $4.76-5.25 \mathrm{~mol} / \mathrm{kg}$. The viscosities of liquid epoxy and hardener are $12000-15000 \mathrm{cps}$ and $45 \mathrm{cps}$, respectively, at room temperature. To prepare epoxy material $(\mathrm{EP}+\mathrm{HD})$, the mix proportions are 50 parts by weight of hardener to 100 parts by weight of liquid epoxy.

2.1.2. Graphene. Graphene was purchased from Graphene Laboratories Inc., USA (product name: AO-3). The graphene nanoplatelets, according to the manufacture's technical data sheet, have a specific surface area of $80 \mathrm{~m}^{2} / \mathrm{g}$; the average lateral size and thickness are $4.5 \mu \mathrm{m}$ and $12 \mathrm{~nm}$, respectively. Figure 3 shows the SEM image of a raw graphene nanoplatelet.

\subsection{Sample Preparation. Graphene samples were weighed in} Sartorius MC210S analytical balance (with the readability of $0.01 \mathrm{mg}$ ) and dispersed in EP by hand mixing for $5 \mathrm{~s}$ gently and then sonicated through a bath sonicator (Grant MXB6) for uniform dispersion. The bath sonicator was rated for an average working power output of $89 \mathrm{~W}$ in aqueous media.

For studying the influence of sonication time on the dispersibility, $0.005 \mathrm{wt} \%$ dispersions were sonicated for different durations ranging from 6 mins to $60 \mathrm{mins}$ at $20^{\circ} \mathrm{C}$. Another part of dispersion was sonicated for $30 \mathrm{mins}$ and then stored for 10 days for studying the reaggregation against storage time. For studying the influence of concentration on the dispersibility, different concentrations ranging from $0.005 \mathrm{wt} \%$ to $0.1 \mathrm{wt} \%$ of samples had been prepared and then sonicated for $30 \mathrm{mins}$ at $20^{\circ} \mathrm{C}$. For studying the influence

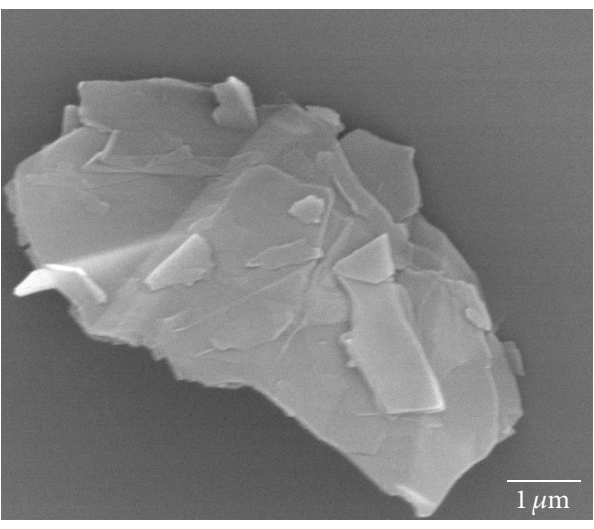

FIGURE 3: SEM image of graphene nanoplatelets.

of sonication temperature on the dispersibility, $0.005 \mathrm{wt} \%$ dispersions were sonicated for 6 mins from $20^{\circ} \mathrm{C}$ to $60^{\circ} \mathrm{C}$. Graphene-HD, graphene-EP + HD dispersions were prepared by the same method accordingly. All samples had been degassed at $-0.1 \mathrm{MPa}$ to remove the entrapped air.

To prepare epoxy/graphene nanocomposites, graphene was first dispersed in hardener by bath sonication for $30 \mathrm{mins}$ at room temperature. Then the suspensions were mixed with liquid epoxy by the ratio of EP:HD of $2: 1$. Following thorough hand mixing for 10 mins, vacuum degassing was carried out to remove the entrapped air. The mixtures were then mould cast and cured at room temperature for $6 \mathrm{~h}$ followed by postcuring at $80^{\circ} \mathrm{C}$ for $6 \mathrm{~h}$.

2.3. Characterization. Light transmittance in the UV-visible spectroscopy (HITACHI U-3000) has been used to quantify the reaggregation of graphene in epoxy system through a series of controlled experiments. Tests were always carried out immediately after the sonication of each dispersion. Standard polystyrene cuvettes with an optical path length of $10 \mathrm{~mm}$ were used for transmittance measurements. Light transmittance of graphene dispersions was recorded versus blank EP, HD, and EP + HD at fixed wavelength of $450 \mathrm{~nm}$. Five specimens were tested for each set of conditions and mean values were then reported. Graphene dispersions were also systematically characterized by optical microscopy.

Tensile, three-point bend tests were conducted by Universal Testing Machine (Instron 3382); the crosshead speed was kept at $2 \mathrm{~mm} / \mathrm{min}$ for all the tests. Tensile properties were measured according to ASTM D638 (Type V geometry) with specimen thickness $4 \mathrm{~mm}$. Three-point bend test was conducted according to ASTM D790 with specimen dimensions of $3 \times 12.7 \times 48 \mathrm{~mm}$. Five specimens were tested for each set of conditions and mean values were then reported.

Dynamic Mechanical Analyser (DMA) (Model 8000, Perkin Elmer) was used to determine the storage modulus $\left(E^{\prime}\right)$ and loss factor $\tan \delta$. Rectangular specimens with dimensions of $2.5 \times 8 \times 30 \mathrm{~mm}$ were tested in single cantilever mode. All tests were carried out by temperature sweep method (temperature ramp from 30 to $180^{\circ} \mathrm{C}$ at $10^{\circ} \mathrm{C} / \mathrm{min}$ ) at a constant frequency of $1 \mathrm{~Hz}$. 


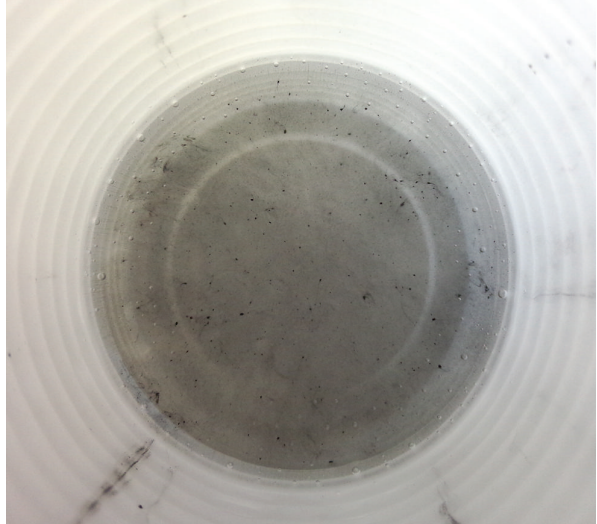

(a)

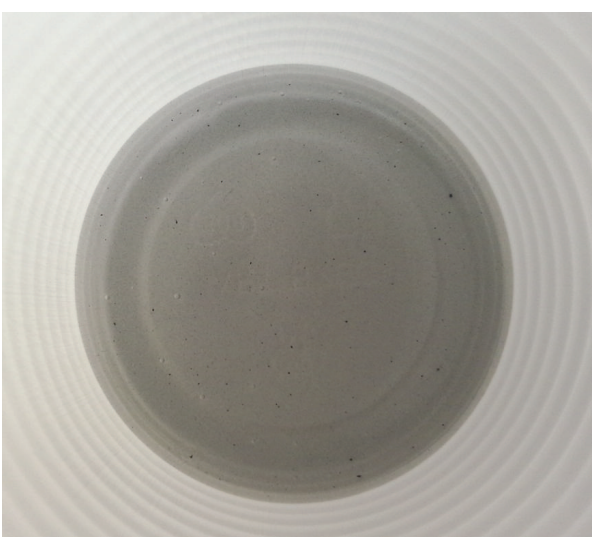

(c)

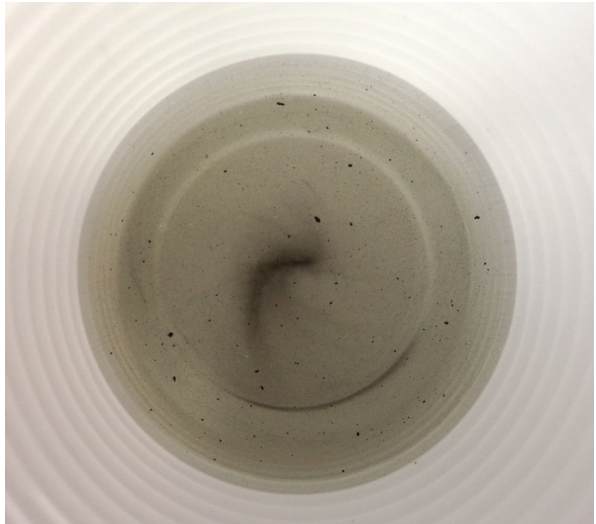

(b)

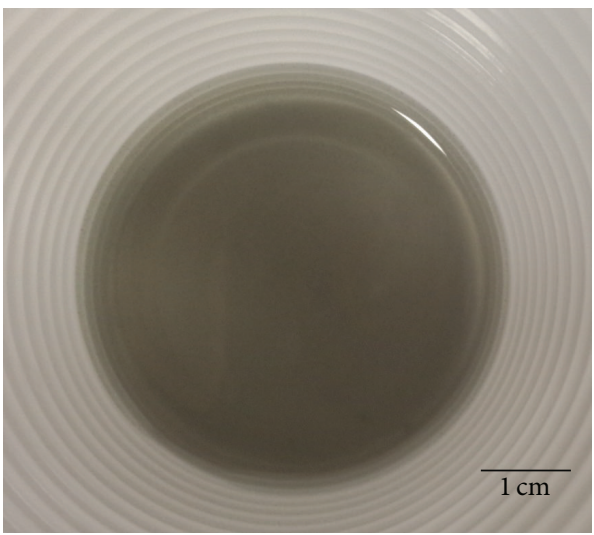

(d)

FIGURE 4: Graphene in EP and HD: (a) graphene-EP before sonication; (b) graphene-HD before sonication; (c) graphene-EP after sonication; and (d) graphene-HD after sonication.

\section{Results and Discussion}

3.1. Reaggregation as a Function of Sonication Time. Sonication is the most widely adopted method to disperse graphene in liquid matrix and has proved to be of high efficiency. Figure 4 shows graphene dispersion in EP and HD before and after sonication.

The light transmittance of graphene dispersion against sonication time is shown in Figure 5. The graphs show a significant drop in the transmittance for the graphene dispersion in HD within the first 12 mins. This high magnitude slope suggests a much higher tendency of graphene to disperse in HD. Before sonication, graphene aggregates lowered light absorbance because of the shielding effects of the bundles [42]. After sonication, the aggregates are dispersed into small aggregates/flakes causing higher light absorption or lower light transmittance. A similar trend was also observed for the graphene dispersion in EP, where light transmittance also decreased with the sonication time. However, the magnitude of the slope is much lower than that of HD due to the high viscosity of $\mathrm{EP}$, making it more difficult for graphene to disperse. It is noteworthy that, as compared to 15 percent drop in $\mathrm{EP}$ and 26 percent drop in $\mathrm{HD}$, there is just 11 percent

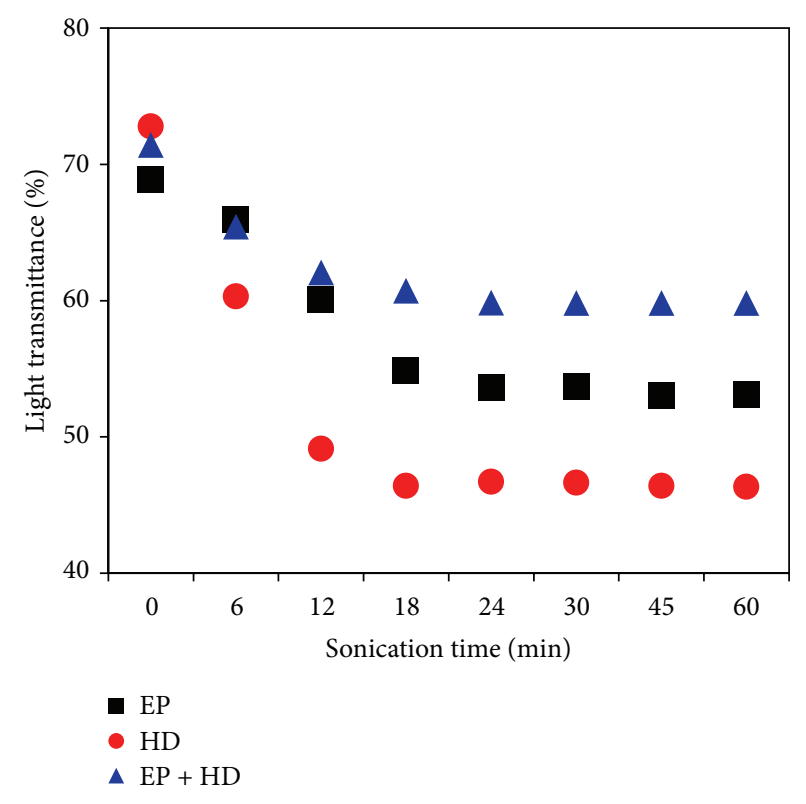

FIGURE 5: Light transmittance of graphene dispersion against sonication time (graphene concentration: $0.005 \mathrm{wt} \%$ ). 


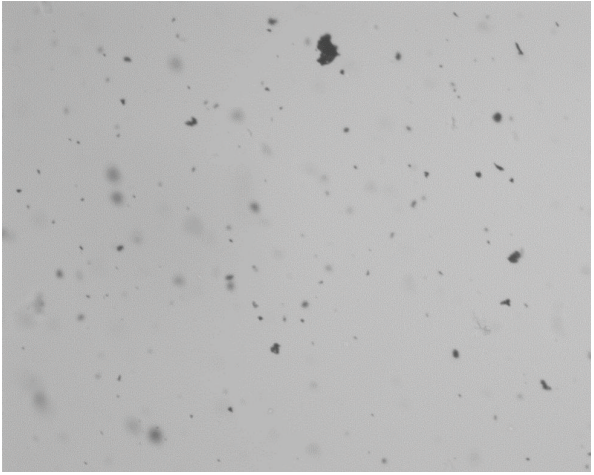

(a)

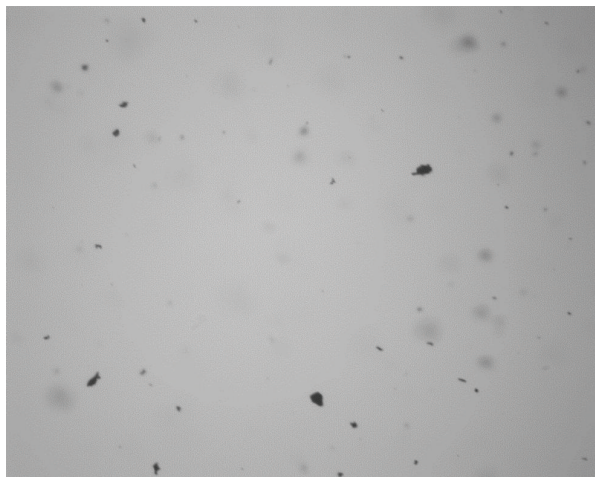

(c)

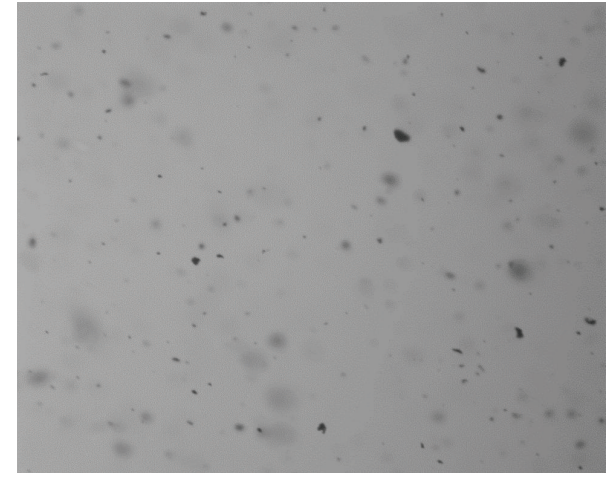

(b)

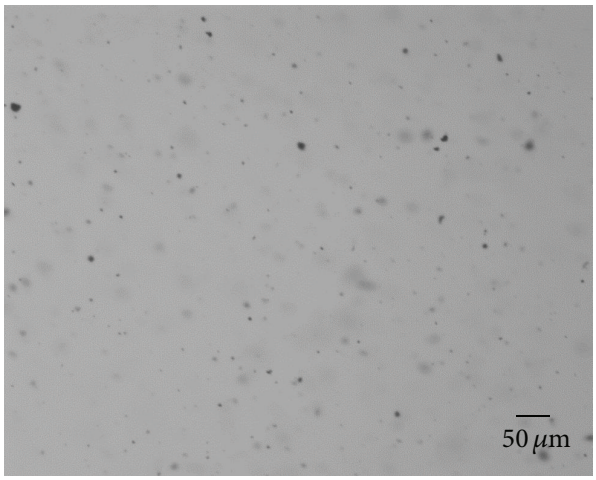

(d)

FIGURE 6: Optical microscopic analyses: (a) graphene-EP before sonication; (b) graphene-HD before sonication; (c) graphene-EP after sonication; and (d) graphene-HD after sonication.

drop in the transmittance for graphene dispersion in EP + HD. This lower decrement in light transmittance suggests nonuniform dispersion, which is due to the curing of epoxy resin while mixed with hardener. After mixing liquid resin with hardener, the resin started to cure immediately. The fast gelling and curing process left only limited time for graphene dispersion. This limited time was not enough to disperse graphene uniformly. Therefore, selection of epoxy with longer curing durations is desirable for preparing epoxy/graphene nanocomposites.

This dispersion of graphene was further analyzed by optical microscopy. Large aggregates before sonication were clearly seen from the sample, as shown in Figures 6(a) and $6(\mathrm{~b})$. After sonication for $60 \mathrm{mins}$, the aggregates were unlocked into small agglomerates/flakes, as shown in Figures 6(c) and 6(d).

This qualitative result shows that the dispersion of graphene in the mixture of EP and HD together has the lowest efficiency because of the curing of resin. As the resin cures, the molecular chain of epoxy becomes fixed and hinders graphene from further dispersion. Due to high viscosity and sticky nature of EP, dispersion of graphene in EP is more difficult, while dispersion of graphene in HD is easier and possesses higher efficiency.

3.2. Reaggregation as a Function of Storage Time. Graphene has tendency to aggregate in the low viscous matrix due to the strong van der Waals force and pi-stacking. It is therefore necessary to understand its reaggregation behavior in order to gain meaningful knowledge about the stability of the dispersion.

Figure 7 shows the light transmittance of graphene dispersion against storage time. Within the first 5 days, the behavior of graphene in EP and that in HD are similar. Both dispersions showed slight increment in light transmittance, which are 5\% and $4 \%$ in $\mathrm{EP}$ and $\mathrm{HD}$, respectively. This increment indicated that some level of reaggregation took place during this time, but very slightly. During 5 to 10 days, the light transmittance did not change, indicating that the dispersions are stable over this time period. The light transmittance of graphene-EP + HD dispersion kept constant, because the system became stable after the epoxy resin was fully cured within 24 hours.

Optical microscopy further confirmed the stability of the dispersion. Figures $8(\mathrm{a})$ and $8(\mathrm{~b})$ show the graphene dispersion in EP and HD tested within 1 min after sonication and Figures 8(c) and 8(d) show the dispersion after 10-day storage. It can be seen that there is no obvious change in the dispersion state, which indicates that the dispersions are in general stable during this time period.

3.3. Reaggregation as a Function of Graphene Concentration. Five series of graphene dispersion with concentrations between $0.005 \%$ and $0.1 \%$ were prepared. Figure 9 shows the 


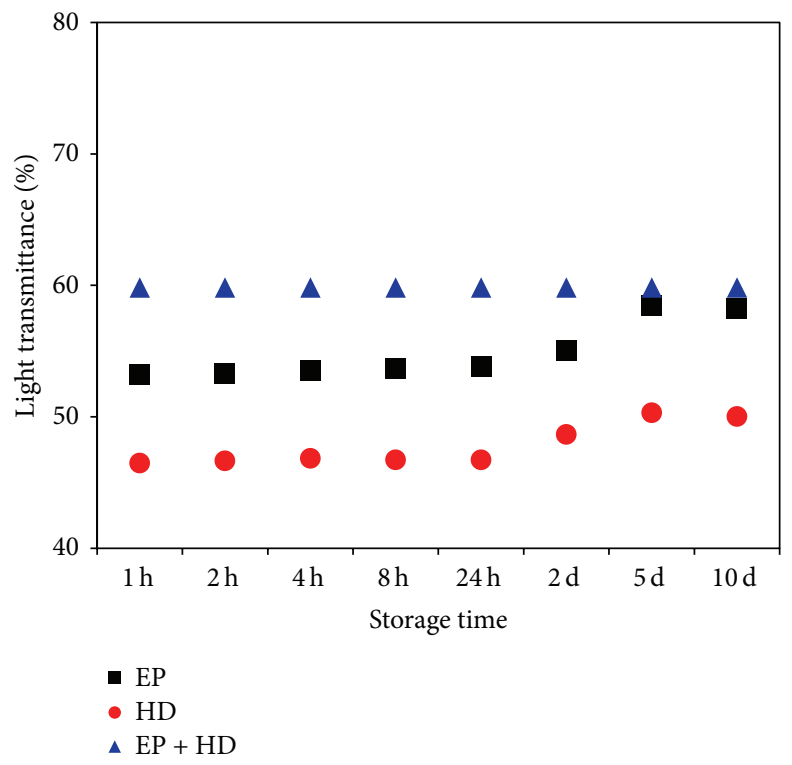

FIGURE 7: Light transmittance of graphene dispersion against storage time (graphene concentration: $0.005 \mathrm{wt} \%$ ).

changes in transparency of graphene dispersions at different concentrations. As can be noticed from the image, suspensions with higher concentration have less light transmission as compared to low concentration suspensions. Samples with concentration higher than $0.025 \mathrm{wt} \%$ are visually all black with none light transmission. It should be noted here that though this is a qualitative analysis, it yields some very meaningful findings for further research work.

As mentioned in Section 3.1, at low concentration, the light transmittance decreased with the decrease of agglomerate/flake size. Figure 10 shows the measured light transmittance against concentration. The light transmittance decreased with the increase of concentration.

Figure 11 depicts the optical photograph of graphene dispersion in EP and $\mathrm{HD}$ with increased concentration after sonicating for 30 mins. We can see that graphene was dispersed in the dispersion because of the sonication. Reaggregation behavior cannot be seen directly here. Because the interparticle distance between dispersed graphene sheets is small at higher concentration, making graphene sheets easier to attract each other, it can be deduced that reaggregation behavior can be more pronounced at higher concentrations. Beside reaggregation, higher graphene concentration also means increased difficulty for uniform dispersion [43], which further hinders the stability of the dispersion.

3.4. Reaggregation as a Function of Sonication Temperature. High temperature accelerates chemical reactions and mobility of molecules in liquid system, which would make graphene nanoplatelets easier to disperse. Five series of samples were prepared with sonication temperatures from 20 to $60^{\circ} \mathrm{C}$ and sonicated for 6 mins. The results are shown in Figure 12. For graphene-HD dispersion, the light transmittance is $60.32 \%$ at $20^{\circ} \mathrm{C}$ after 6 mins of sonication; however, it reaches $46.42 \%$ at $50^{\circ} \mathrm{C}$ within 6 mins. This value could only be achieved after 18 mins sonication at $20^{\circ} \mathrm{C}$ as can be seen in Figure 5 (Section 3.1). Similarly, the light transmittance of graphene-EP dispersion was $53.21 \%$ at $60^{\circ} \mathrm{C}$ after 6 mins sonication, which was only achieved after $24 \mathrm{mins}$ at $20^{\circ} \mathrm{C}$ (Figure 5). For graphene-EP + HD dispersion, longer sonication duration will lead to the curing of the resin, which would hinder any dispersion. Under higher temperature, sonication at $50^{\circ} \mathrm{C}$ for 6 mins is enough to reach uniform dispersion state as confirmed in Figure 12.

These results confirm that dispersion is strongly dependent on the sonication temperature. Theoretically, appropriate dispersion is achieved by providing the right energy to the system, which is normally accomplished by sonication. However, for fine powders or strongly bonded aggregates, higher temperatures are preferred for increased mobility of chemical species and effective debundling of agglomerates.

3.5. Mechanical Properties as a Function of Concentration in Nanocomposites. The degree of dispersion correlates directly with the mechanical properties of nanocomposites; however, the reinforcement effect at low graphene concentration might be tiny. For analysing the effect of dispersion on the mechanical properties, nanocomposites with higher loading were prepared, at graphene concentrations of $0.1 \mathrm{wt} \%, 0.3 \mathrm{wt} \%$, $0.5 \mathrm{wt} \%$, and $1 \mathrm{wt} \%$, respectively.

The storage modulus $\left(E^{\prime}\right)$ and $\tan \delta$ values with respect to temperature were studied to assess the role of the nanocomposites under stress (Figure 13). As summarized in Table 1, the storage modulus of the nanocomposites at room temperature increased with increasing graphene concentration up to $0.3 \mathrm{wt} \%$ (Figure 13(a)). The nanocomposites with a graphene concentration of $0.3 \mathrm{wt} \%$ show the highest storage modulus of $E^{\prime}=2.16 \mathrm{GPa}$, while the pure epoxy shows $E^{\prime}=1.66 \mathrm{GPa}$, that is, $30 \%$ increment. The value reached maximum at the loading of $0.3 \mathrm{wt} \%$. This was due to the homogeneous dispersion being limited up to the graphene concentration of $0.3 \mathrm{wt} \%$. 


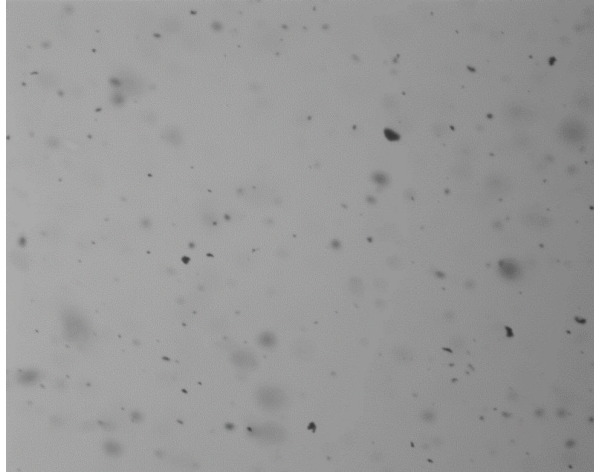

(a)

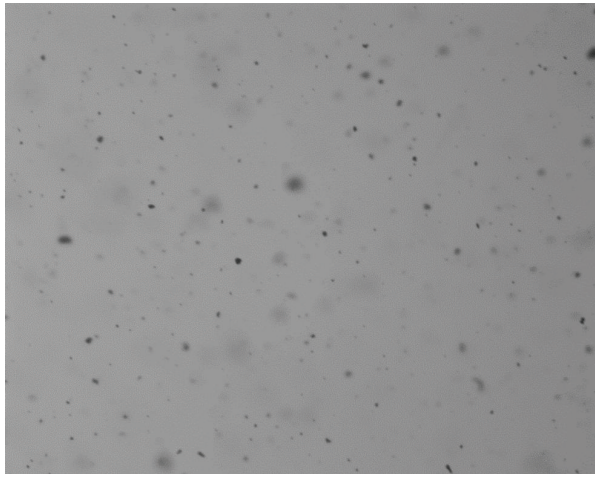

(c)

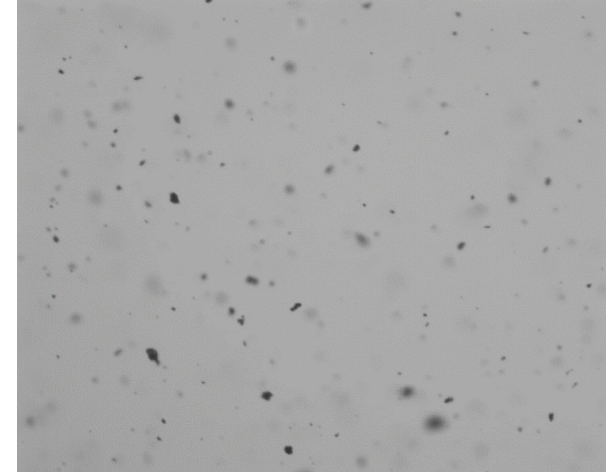

(b)

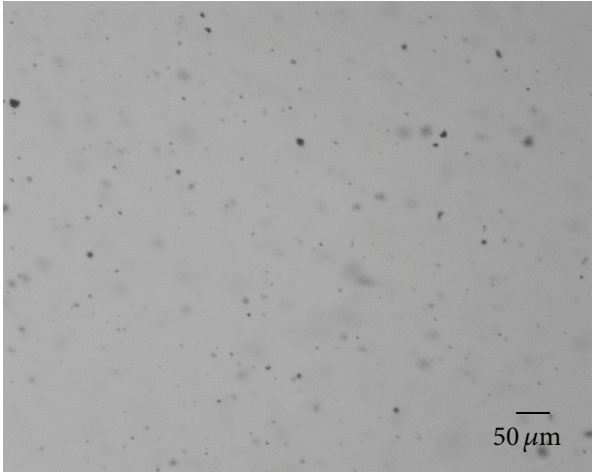

(d)

FIGURE 8: Optical microscopic analyses: (a) graphene-EP storage for $1 \mathrm{~min}$; (b) graphene-HD storage for 10 days; (c) graphene-EP storage for $1 \mathrm{~min}$; and (d) graphene-HD storage for 10 days.

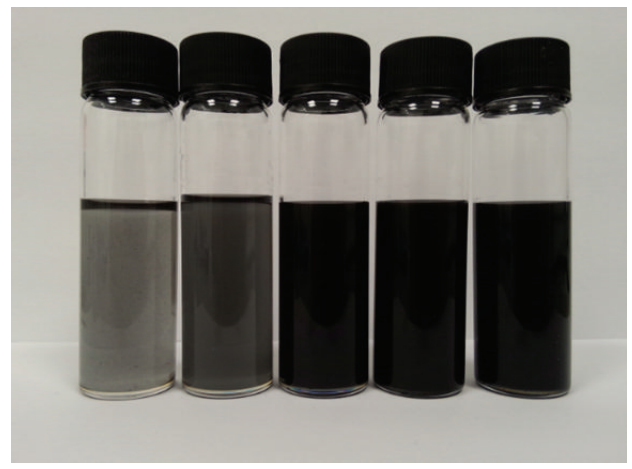

(a)

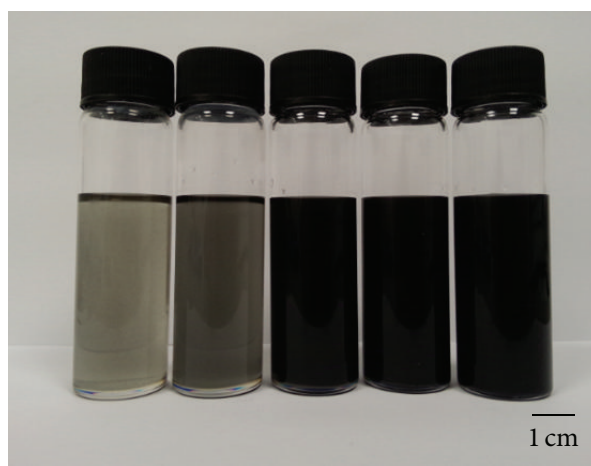

(b)

FIGURE 9: Qualitative analyses of (a) graphene-EP and (b) graphene-HD (concentration from left to right: $0.005 \mathrm{wt} \% ; 0.0125 \mathrm{wt} \% ; 0.025 \mathrm{wt} \%$; $0.05 \mathrm{wt} \% ; 0.1 \mathrm{wt} \%)$.

Figure 13(b) shows the temperature dependence of epoxy/graphene nanocomposites' $\tan \delta$ values. The $\tan \delta$ value is defined as loss factor, which is the ratio of loss modulus to storage modulus $\left(E^{\prime \prime} / E^{\prime}\right)$, and is very sensitive to structural transformation of solid materials. The maximum peak of $\tan \delta$ represents the glass transition temperature $\left(T_{g}\right)$ of material and is shown in Table 1 . The $T_{g}$ value of nanocomposites shifts to higher temperature, from $93.37^{\circ} \mathrm{C}$ (pure epoxy) to $99.08^{\circ} \mathrm{C}$ (graphene concentration $0.3 \mathrm{wt} \%$ ). The rise in $T_{g}$ is associated with restriction in molecular motion and reduction in free volume due to the uniform dispersion of fillers. This is responsible for decreasing the mobility of the polymer chains in response to an applied thermal energy. For concentrations above $0.5 \mathrm{wt} \%$, a drop 


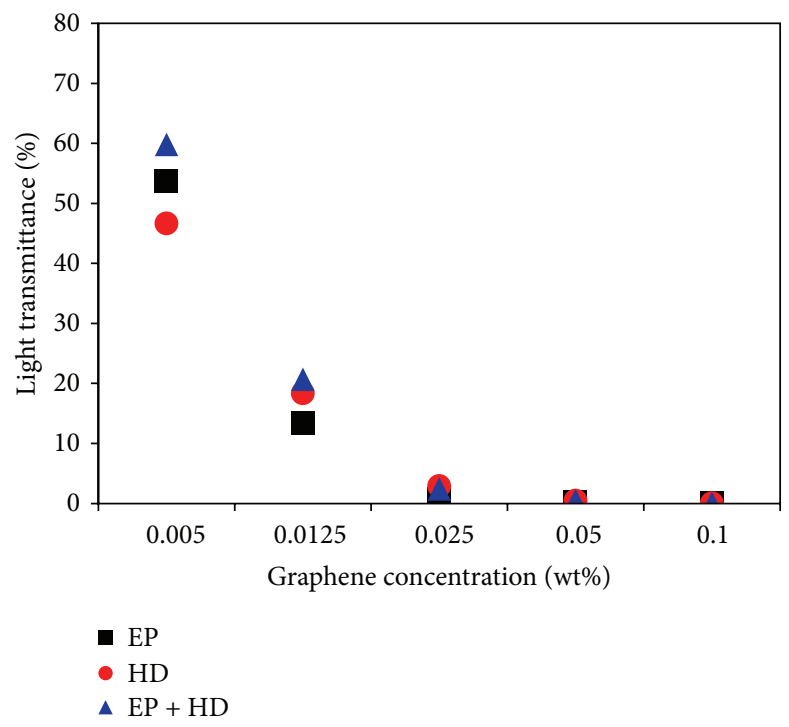

FIGURE 10: Light transmittance of graphene dispersion against concentration (graphene concentration: $0.005 \mathrm{wt} \%$ ).
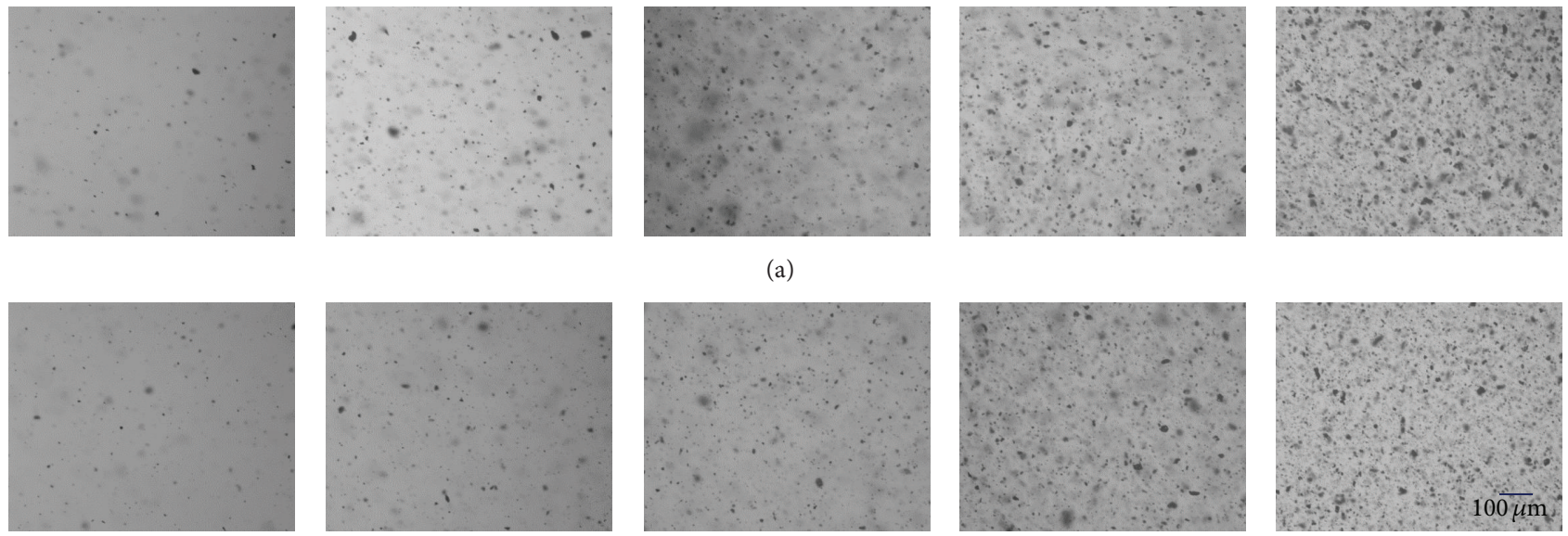

(b)
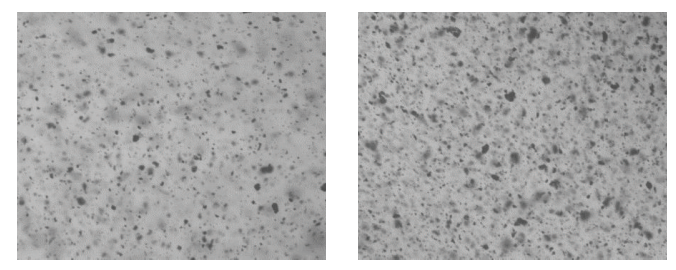

(a)

FIGURE 11: Optical microscope images of graphene dispersion with increased concentration in (a) liquid epoxy and (b) hardener.

TABLE 1: Thermal mechanical properties of epoxy/graphene nanocomposites.

\begin{tabular}{lcc}
\hline Graphene concentration $(w t \%)$ & Storage modulus $(\mathrm{GPa})$ & $T_{g}\left({ }^{\circ} \mathrm{C}\right)$ \\
\hline 0 & 1.66 & 93.37 \\
0.1 & 2.06 & 97.15 \\
0.3 & 2.16 & 99.08 \\
0.5 & 1.96 & 98.35 \\
1 & 1.86 & 97.12 \\
\hline
\end{tabular}

in $T_{g}$ was recorded. This is due to the presence of larger aggregation sites within the nanocomposites as reported in the literature $[44,45]$. The aggregates are physical defects in the material, which hinder the curing and lead to the decrease in crosslinking density $[46,47]$.
The incorporation of graphene also significantly influenced the tensile and flexural properties of nanocomposites, as shown in Figure 14. The figure shows the average tensile strength for pure epoxy is $57.2 \mathrm{MPa}$, and the tensile strength for nanocomposites with $0.3 \mathrm{wt} \%$ graphene loading is $64.4 \mathrm{MPa}$, which is an increment of $12.6 \%$. The flexural strength also shows a $10 \%$ increment at graphene loading of $0.3 \mathrm{wt} \%$. These remarkable increments in the tensile and flexural strengths were due to the uniform dispersion of graphene in the epoxy matrix, which formed a perfect cocontinuous structure. Further increasing the graphene loading above $0.5 \mathrm{wt} \%$ led to a decrease in both the tensile and flexural strengths. This is due to the nonuniform dispersion of graphene and the aggregates may have acted as the defect center; thus the increased stress concentration led to the decreasing of the properties. As a result, it was suggested that graphene can be effectively dispersed in epoxy matrix 


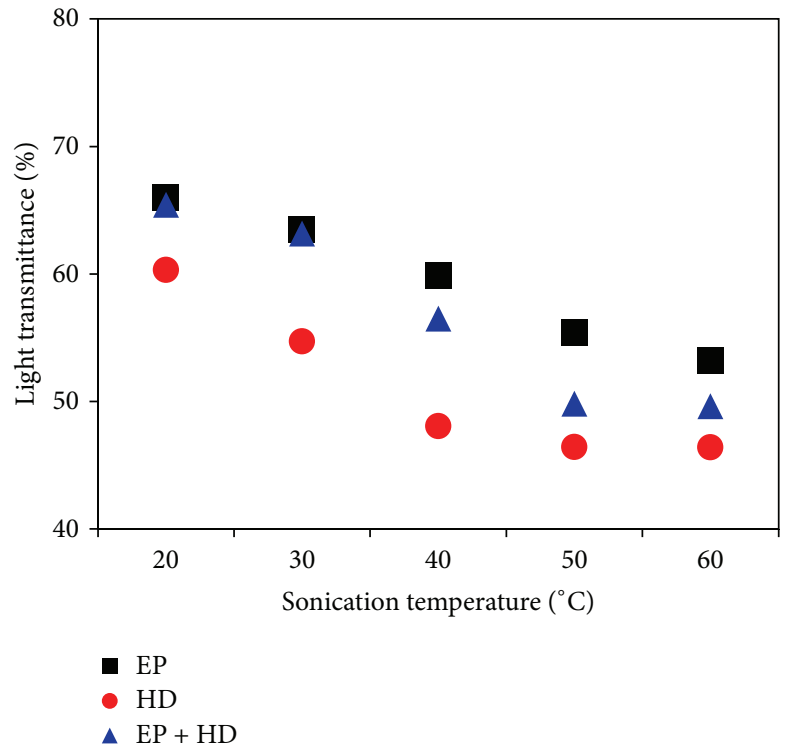

FIGURE 12: Light transmittance of graphene dispersion against sonication temperature (graphene concentration: $0.005 \mathrm{wt} \%$ ).

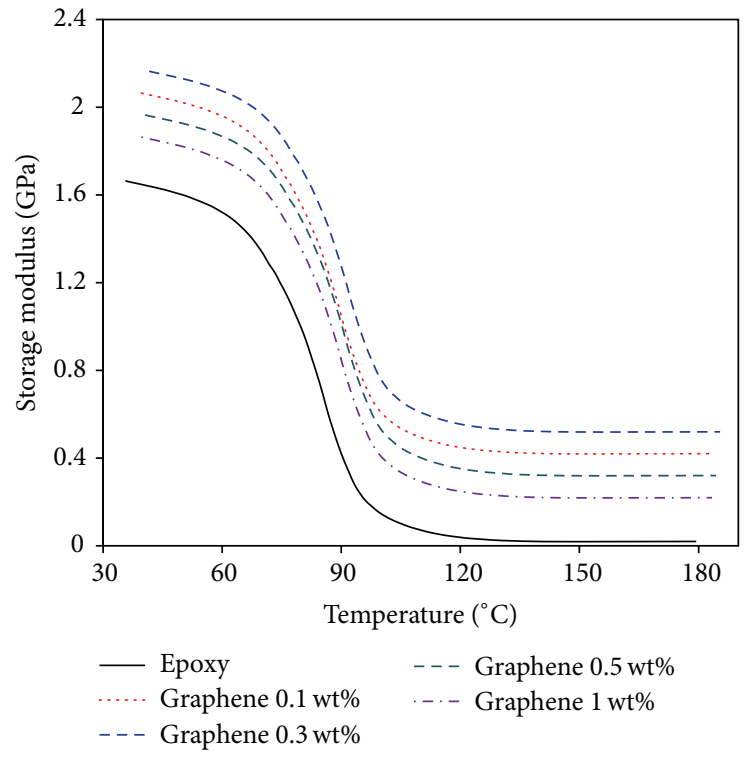

(a)

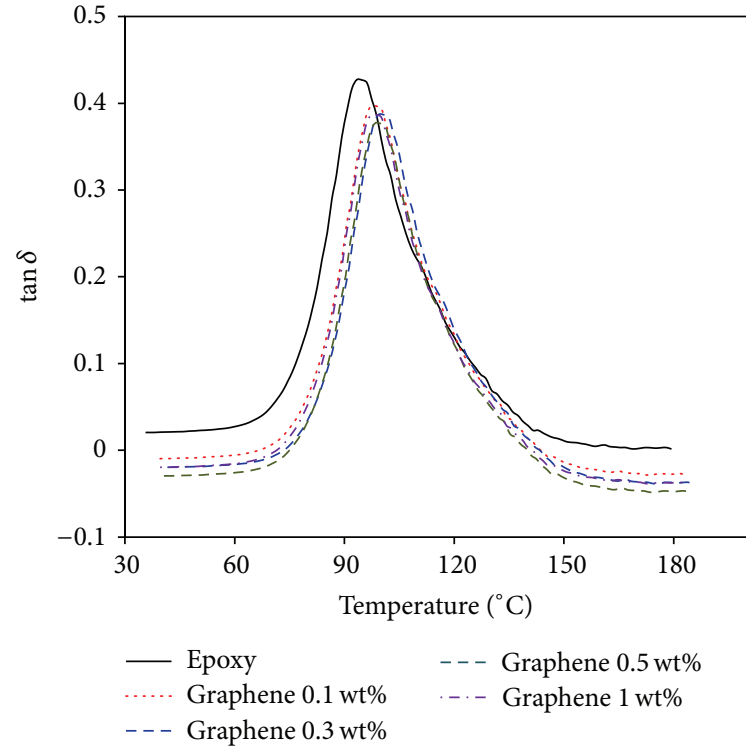

(b)

FIGURE 13: Dynamic mechanical analysis of epoxy/graphene nanocomposites: (a) storage modulus and (b) $\tan \delta$.

when the loading is lower than $0.3 \mathrm{wt} \%$, which is consistent with the DMA test. While increasing the concentration of graphene above this loading, the restacking of graphene leads to the aggregates, saturating the reinforcing efficiency of the nanocomposites. However, in the case of tensile and flexural moduli, the value reached maximum at $1 \mathrm{wt} \%$ of graphene loading. This continuous increment shows that, with the incorporation of rigid fillers, the epoxy/graphene nanocomposites are resilient towards elastic deformation. The results (i.e., changes of modulus and strength) are in accordance with other reports [31,48-50]. Overall, as compared to pure epoxy, both the tensile and flexural properties of the nanocomposites were improved. These increments suggest strong reinforcement effect of graphene in epoxy matrix.

\section{Conclusion}

Dispersion of graphene in matrix plays crucial role for the performance of nanocomposites. Reaggregation, that is, agglomeration with the passage of time, has often been underestimated and even ignored. This work has measured the reaggregation of graphene in two-component epoxy 


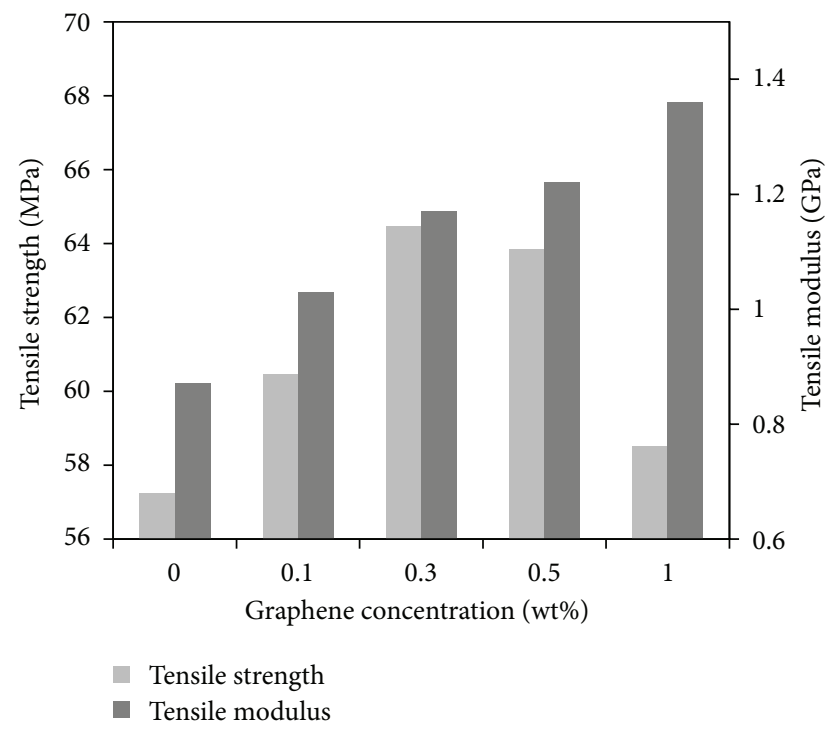

(a)

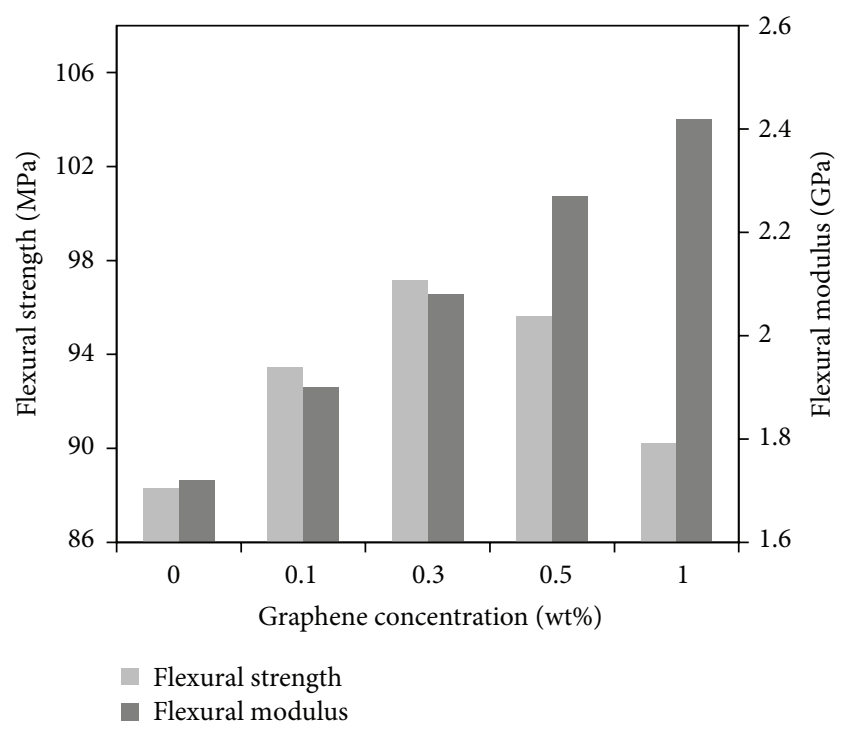

(b)

FIGURE 14: Mechanical properties of epoxy/graphene nanocomposites: (a) tensile properties and (b) flexural properties.

system using optical transmittance spectroscopy. The results show that temperature and viscosity significantly contribute to the dispersion of graphene. Graphene tends to disperse easily under high temperature in low viscosity system; beside this, lower concentration yielded lower reaggregation profile (size and trend) and vice versa. The mechanical properties of the nanocomposites were significantly improved as compared to pure epoxy with the incorporation of graphene, which suggested that uniform dispersion plays a critical role.

\section{Conflict of Interests}

The authors declare that there is no conflict of interests regarding the publication of this paper.

\section{Acknowledgment}

The authors would like to thank the Department of Mechanical and Construction Engineering, Northumbria University, for the provision of research facilities, without which the collection and analysis of relevant data were not possible.

\section{References}

[1] K. S. Novoselov, A. K. Geim, S. V. Morozov et al., "Electric field effect in atomically thin carbon films," Science, vol. 306, no. 5696, pp. 666-669, 2004.

[2] A. K. Geim and K. S. Novoselov, "The rise of graphene," Nature Materials, vol. 6, no. 3, pp. 183-191, 2007.

[3] Y. T. Park, Y. Qian, C. Chan et al., "Epoxy toughening with low graphene loading," Advanced Functional Materials, vol. 25, no. 4, pp. 575-585, 2015.

[4] L. Yue, G. Pircheraghi, S. A. Monemian, and I. Manas-Zloczower, "Epoxy composites with carbon nanotubes and graphene nanoplatelets-dispersion and synergy effects," Carbon, vol. 78, pp. 268-278, 2014.
[5] N. Saurín, J. Sanes, and M. D. Bermúdez, "Effect of graphene and ionic liquid additives on the tribological performance of epoxy resin,” Tribology Letters, vol. 56, no. 1, pp. 133-142, 2014.

[6] F. Inam, "Epoxy—the hub for the most versatile polymer with exceptional combination of superlative features," Epoxy, vol. 1, pp. 1-2, 2014.

[7] J. Wei, T. Vo, and F. Inam, "Epoxy/graphene nanocompositesprocessing and properties: a review," RSC Advances, vol. 5, no. 90, pp. 73510-73524, 2015.

[8] H. Pathangi, P. M. Vereecken, A. Klekachev, G. Groeseneken, and A. Witvrouw, "Quantifying the aggregation factor in carbon nanotube dispersions by absorption spectroscopy," The Journal of Nanoscience, vol. 2014, Article ID 328627, 13 pages, 2014.

[9] F. Inam and T. Peijs, "Re-aggregation of carbon nanotubes in two-component epoxy system," Journal of Nanostructured Polymers and Nanocomposites, vol. 2, no. 3, pp. 87-95, 2006.

[10] Y.-J. Wan, L.-C. Tang, D. Yan et al., "Improved dispersion and interface in the graphene/epoxy composites via a facile surfactant-assisted process," Composites Science and Technology, vol. 82, pp. 60-68, 2013.

[11] Y. Ni, L. Chen, K. Teng et al., "Superior mechanical properties of epoxy composites reinforced by 3D interconnected graphene skeleton," ACS Applied Materials and Interfaces, vol. 7, no. 21, pp. 11583-11591, 2015.

[12] S. Chandrasekaran, N. Sato, F. Tölle, R. Mülhaupt, B. Fiedler, and K. Schulte, "Fracture toughness and failure mechanism of graphene based epoxy composites," Composites Science and Technology, vol. 97, pp. 90-99, 2014.

[13] B. Qi, Z. Yuan, S. Lu et al., "Mechanical and thermal properties of epoxy composites containing graphene oxide and liquid crystalline epoxy," Fibers and Polymers, vol. 15, no. 2, pp. 326333, 2014.

[14] W. Yang, E. Widenkvist, U. Jansson, and H. Grennberg, "Stirring-induced aggregation of graphene in suspension," New Journal of Chemistry, vol. 35, no. 4, pp. 780-783, 2011. 
[15] W. He, W. Zhang, Y. Li, and X. Jing, "A high concentration graphene dispersion stabilized by polyaniline nanofibers," Synthetic Metals, vol. 162, no. 13-14, pp. 1107-1113, 2012.

[16] Z. Wang, J. Luo, and G.-L. Zhao, "Dielectric and microwave attenuation properties of graphene nanoplatele--epoxy composites," AIP Advances, vol. 4, no. 1, Article ID 017139, 2014.

[17] S. Liu, H. Yan, Z. Fang, Z. Guo, and H. Wang, "Effect of graphene nanosheets and layered double hydroxides on the flame retardancy and thermal degradation of epoxy resin," $R S C$ Advances, vol. 4, no. 36, pp. 18652-18659, 2014.

[18] G. Yu and P. Wu, "Effect of chemically modified graphene oxide on the phase separation behaviour and properties of an epoxy/ polyetherimide binary system," Polymer Chemistry, vol. 5, no. 1, pp. 96-104, 2014.

[19] D. Cai and M. Song, "Recent advance in functionalized graphene/polymer nanocomposites," Journal of Materials Chemistry, vol. 20, no. 37, pp. 7906-7915, 2010.

[20] X. Huang, X. Qi, F. Boey, and H. Zhang, "Graphene-based composites," Chemical Society Reviews, vol. 41, no. 2, pp. 666686, 2012.

[21] A. S. Wajid, H. S. Tanvir Ahmed, S. Das, F. Irin, A. F. Jankowski, and M. J. Green, "High-performance pristine graphene/epoxy composites with enhanced mechanical and electrical properties," Macromolecular Materials and Engineering, vol. 298, no. 3, pp. 339-347, 2013.

[22] C. E. Hamilton, J. R. Lomeda, Z. Sun, J. M. Tour, and A. R. Barron, "High-yield organic dispersions of unfunctionalized graphene," Nano Letters, vol. 9, no. 10, pp. 3460-3462, 2009.

[23] A. Zurutuza and C. Marinelli, "Challenges and opportunities in graphene commercialization," Nature Nanotechnology, vol. 9, no. 10 , pp. 730-734, 2014.

[24] S.-Z. Zu, D. Zhou, and B.-H. Han, "Supramolecular surface modification and dispersion of graphene in water and organic solvents," Journal of Nanoscience and Nanotechnology, vol. 13, no. 2, pp. 946-953, 2013.

[25] J. Jia, X. Sun, X. Lin, X. Shen, Y.-W. Mai, and J.-K. Kim, “Exceptional electrical conductivity and fracture resistance of $3 \mathrm{D}$ interconnected graphene foam/epoxy composites," ACS Nano, vol. 8, no. 6, pp. 5774-5783, 2014.

[26] Y. Zhu, S. Murali, W. Cai et al., "Graphene and graphene oxide: synthesis, properties, and applications," Advanced Materials, vol. 22, no. 35, pp. 3906-3924, 2010.

[27] E.-Y. Choi, W. S. Choi, Y. B. Lee, and Y.-Y. Noh, "Production of graphene by exfoliation of graphite in a volatile organic solvent," Nanotechnology, vol. 22, no. 36, Article ID 365601, 2011.

[28] X. Wang, J. Jin, and M. Song, "An investigation of the mechanism of graphene toughening epoxy," Carbon, vol. 65, pp. 324333, 2013.

[29] Z. Li, R. Wang, R. J. Young et al., "Control of the functionality of graphene oxide for its application in epoxy nanocomposites," Polymer, vol. 54, no. 23, pp. 6437-6446, 2013.

[30] S. Liu, H. Yan, Z. Fang, and H. Wang, "Effect of graphene nanosheets on morphology, thermal stability and flame retardancy of epoxy resin," Composites Science and Technology, vol. 90, pp. 40-47, 2014.

[31] I. Zaman, H.-C. Kuan, Q. Meng et al., "A facile approach to chemically modified graphene and its polymer nanocomposites," Advanced Functional Materials, vol. 22, no. 13, pp. 27352743, 2012 .

[32] Q. Meng, J. Jin, R. Wang et al., "Processable 3-nm thick graphene platelets of high electrical conductivity and their epoxy composites," Nanotechnology, vol. 25, no. 12, Article ID 125707, 2014.

[33] L. Chen, S. Chai, K. Liu et al., "Enhanced epoxy/silica composites mechanical properties by introducing graphene oxide to the interface," ACS Applied Materials and Interfaces, vol. 4, no. 8, pp. 4398-4404, 2012.

[34] Y. Zhang, Y. Wang, J. Yu, L. Chen, J. Zhu, and Z. Hu, “Tuning the interface of graphene platelets/epoxy composites by the covalent grafting of polybenzimidazole," Polymer, vol. 55, no. 19, pp. 4990-5000, 2014.

[35] F. Ren, G. Zhu, P. Ren, Y. Wang, and X. Cui, "In situ polymerization of graphene oxide and cyanate ester-epoxy with enhanced mechanical and thermal properties," Applied Surface Science, vol. 316, no. 1, pp. 549-557, 2014.

[36] S. H. Song, K. H. Park, B. H. Kim et al., "Enhanced thermal conductivity of epoxy-graphene composites by using nonoxidized graphene flakes with non-covalent functionalization," Advanced Materials, vol. 25, no. 5, pp. 732-737, 2013.

[37] A. Y. W. Sham and S. M. Notley, "A review of fundamental properties and applications of polymer-graphene hybrid materials," Soft Matter, vol. 9, no. 29, pp. 6645-6653, 2013.

[38] L.-C. Tang, Y.-J. Wan, D. Yan et al., "The effect of graphene dispersion on the mechanical properties of graphene/epoxy composites," Carbon, vol. 60, pp. 16-27, 2013.

[39] K. Hu, D. D. Kulkarni, I. Choi, and V. V. Tsukruk, "Graphenepolymer nanocomposites for structural and functional applications," Progress in Polymer Science, vol. 39, no. 11, pp. 1934-1972, 2014.

[40] V. Mittal, "Functional polymer nanocomposites with graphene: a review," Macromolecular Materials and Engineering, vol. 299, no. 8, pp. 906-931, 2014.

[41] R. K. Layek and A. K. Nandi, "A review on synthesis and properties of polymer functionalized graphene," Polymer, vol. 54, no. 19, pp. 5087-5103, 2013.

[42] A. V. Naumov, S. Ghosh, D. A. Tsyboulski, S. M. Bachilo, and R. B. Weisman, "Analyzing absorption backgrounds in singlewalled carbon nanotube spectra," ACS Nano, vol. 5, no. 3, pp. 1639-1648, 2011.

[43] H. Kim, A. A. Abdala, and C. W. Macosko, "Graphene/polymer nanocomposites," Macromolecules, vol. 43, no. 16, pp. 65156530, 2010.

[44] K.-S. Kim, I.-Y. Jeon, S.-N. Ahn, Y.-D. Kwon, and J.-B. Baek, "Edge-functionalized graphene-like platelets as a co-curing agent and a nanoscale additive to epoxy resin," Journal of Materials Chemistry, vol. 21, no. 20, pp. 7337-7342, 2011.

[45] D. Galpaya, M. Wang, G. George, N. Motta, E. Waclawik, and C. Yan, "Preparation of graphene oxide/epoxy nanocomposites with significantly improved mechanical properties," Journal of Applied Physics, vol. 116, no. 5, Article ID 053518, 2014.

[46] S.-H. Liao, P.-L. Liu, M.-C. Hsiao et al., "One-step reduction and functionalization of graphene oxide with phosphorus-based compound to produce flame-retardant epoxy nanocomposite," Industrial and Engineering Chemistry Research, vol. 51, no. 12, pp. 4573-4581, 2012.

[47] B. Qi, S. R. Lu, X. E. Xiao, L. L. Pan, F. Z. Tan, and J. H. Yu, "Enhanced thermal and mechanical properties of epoxy composites by mixing thermotropic liquid crystalline epoxy grafted graphene oxide," Express Polymer Letters, vol. 8, no. 7, pp. 467479, 2014.

[48] M. M. Shokrieh, S. M. Ghoreishi, M. Esmkhani, and Z. Zhao, "Effects of graphene nanoplatelets and graphene nanosheets 
on fracture toughness of epoxy nanocomposites," Fatigue \& Fracture of Engineering Materials \& Structures, vol. 37, no. 10, pp. 1116-1123, 2014.

[49] T. Jiang, T. Kuila, N. H. Kim, and J. H. Lee, "Effects of surfacemodified silica nanoparticles attached graphene oxide using isocyanate-terminated flexible polymer chains on the mechanical properties of epoxy composites," Journal of Materials Chemistry A, vol. 2, no. 27, pp. 10557-10567, 2014.

[50] Y.-J. Wan, L.-C. Tang, L.-X. Gong et al., "Grafting of epoxy chains onto graphene oxide for epoxy composites with improved mechanical and thermal properties," Carbon, vol. 69, pp. 467-480, 2014. 

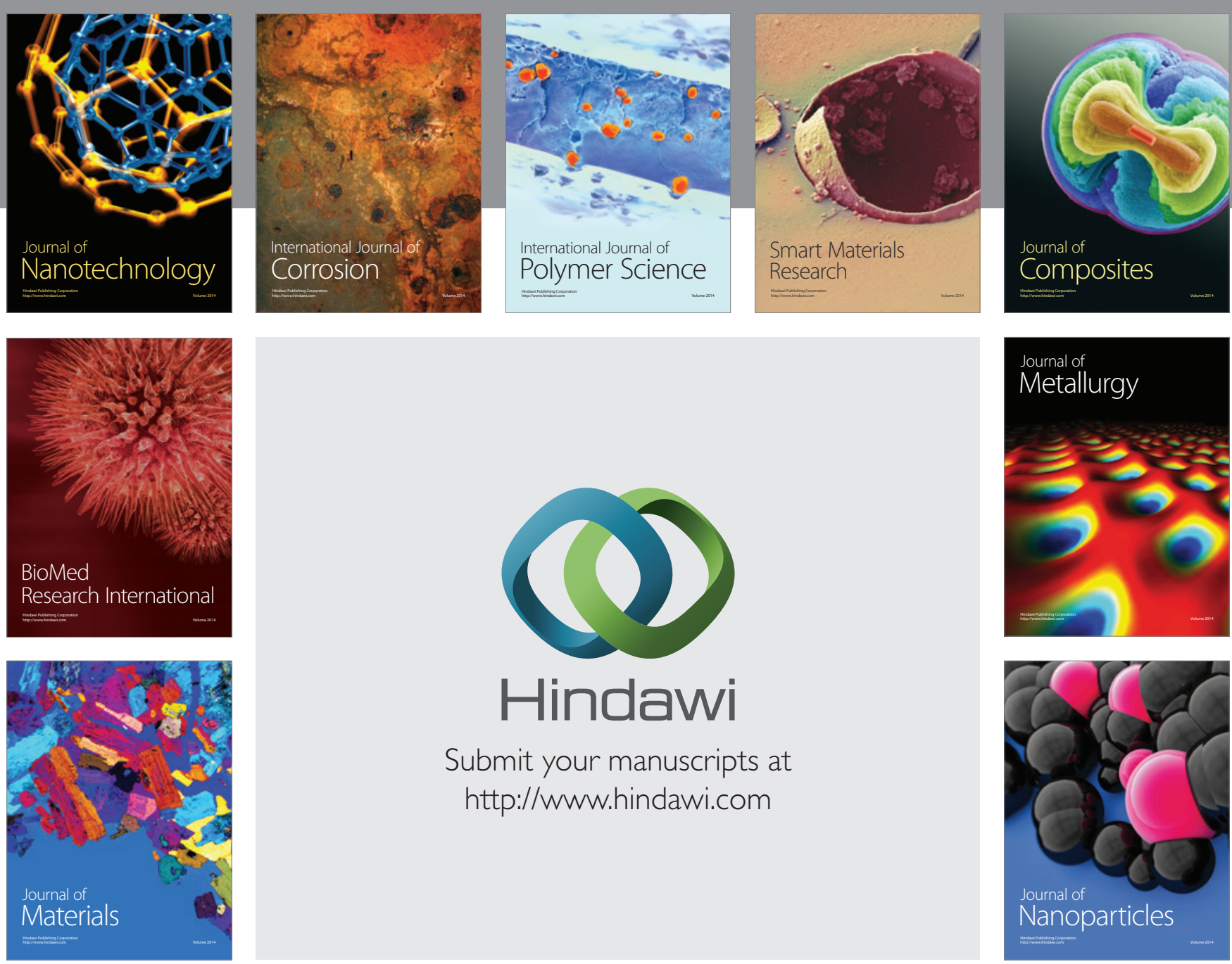

Submit your manuscripts at http://www.hindawi.com
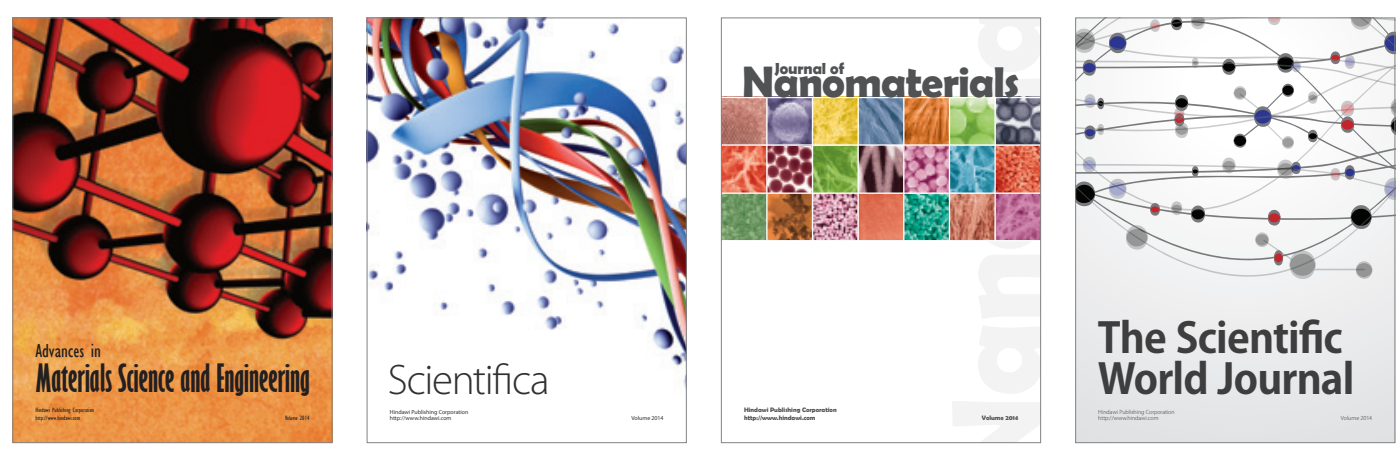

\section{The Scientific World Journal}
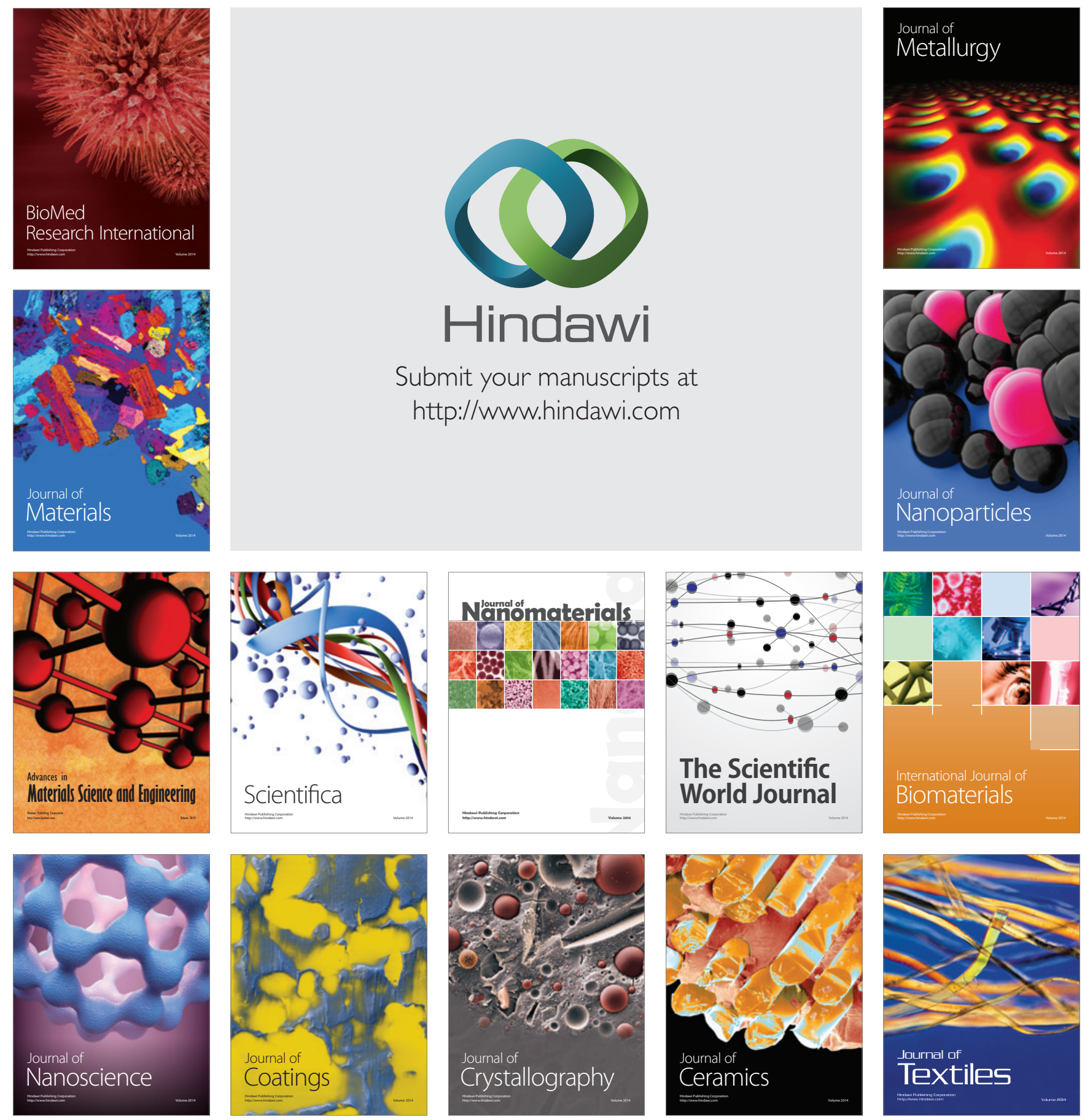